\title{
Significance of anatomical variations of the lateral circumflex femoral artery for the tensor fasciae latae flapping
}

\author{
A. Vuksanovic-Bozaric, N. Radojevic, D. Muhovic, M. Abramovic, M. Radunovic \\ Faculty of Medicine, University of Montenegro, Podgorica, Montenegro \\ [Received 30 August 2014; Accepted 13 November 2014]
}

The tensor fasciae latae (TFL) muscle is commonly used in plastic and reconstructive surgery as a transpositional or a free flap, in order to repair different kinds of defects. In most cases its vascularisation is provided by an ascending branch of lateral circumflex femoral artery (LCFA), which gives different numbers of branches and enters the TFL muscle in different manners. The represented study deals with the arterial vascularisation of the TFL muscle: the entrance of the vascular stalk branches; variations of the LCFA bifurcation's angle; and the skin area of vascularisation. The study was performed on both lower limbs of a 100 foetal and 10 adult cadavers. The LCFA was injected with micropaque solution, afterwards fixed and preserved in 10\% formalin solution. Microdissection was performed under magnifying glass and surgical microscope. Analysis of adult cadavers was performed to determine the skin area vascularised by perforating blood vessels from the TFL muscle, by injecting methylene-blue dye into the artery, prior to which all branches of the LCFA, besides the ascending branch, were ligated. The research of a 100 foetal cadavers showed that the LCFA with its ascending branch ensured the blood supply to the muscle. In 85\% it gave two branches, the ascending and the descending one, with the angle of bifurcation circa $90^{\circ}$ in $73 \%$ of cases. The ascending branch can give 0 or more terminal branches, or even form an arterial net. Skin area affected with dye ranged from $18 \times 22 \mathrm{~cm}$ to $23 \times 28 \mathrm{~cm}$ and is in positive correlation with the LCFA length and diameter. The understanding of the presented variations have an exceptional significance in planning and applying the TFL flap, especially free flap, in successful repairing and covering the defects, as well as in preventing postoperative complications. (Folia Morphol 2015; 74, 3: 389-395)

Key words: tensor fasciae latae, lateral circumflex femoral artery, reconstructive surgery, muscle flap, preventing flap necrosis, anatomical variations

\section{INTRODUCTION}

Reconstruction of massive soft tissue defects is leading issue in plastic and reconstructive surgery, usually after tumourectomy, trauma, multiple surgical interventions, or decubitus formation in immobile patients. Excisions of soft tissue tumours from trunk wall can leave disfiguring and difficultly restored defects, exposing some vital parts of the body, usually large vessels $[1,5,11,33,38]$.

Address for correspondence: N. Radojevic, MD, MSc, Faculty of Medicine, University of Montenegro, Ljubljanska 1, 20000 Podgorica, Montenegro, tel: +382 69340 510,fax: +382 20412 283, e-mail: com_nr@yahoo.com 
The tensor fasciae latae (TFL) flap is a versatile flap with many different applications in plastic and reconstructive surgery. It was first described as a pedicled rotation flap in 1934 [38], and then in 1978 as a free flap by Hill et al. [13]. It is a myocutaneous flap that incorporates the TFL muscle, fascia lata and the overlying skin. For the defects of groin, perineum and lower abdomen up to the umbilicus, the TFL flap may be mobilised and rotated as a pedicled flap (small and mid-sized defects within the arch of rotation of the flap), and for the abdominal defects superior to the level of the umbilicus it can be transferred as a free flap. It offers a completely autologous, single-stage reconstructive solution. In the cases of free flaps the innervation of the TFL muscle is lost, and therefore its tone and bulges as well, so it is functionally passive $[11,27,33]$.

The blood supply of the TFL flap has been described as being through the lateral circumflex artery (LCFA) of the profunda femoris artery (PFA) [13, 15, 28]. LCFA is routinely a lateral branch of PFA, near the root. It inclines between the anterior and the posterior division of the femoral nerve, posterior to the sartorius and the rectus femoris muscles, then ends by dividing into the ascending, transverse and descending branches. The ascending branch runs under the TFL muscle and anastomosis with the superior gluteal and the deep circumflex iliac arteries and supplies the greater trochanter, the head and the neck of femur $[13,15,28,29,31]$. Some authors describe that LCFA gives only the ascending and the descending branch, while the transverse one is the branch of the ascending one $[17,26]$. The TFL flap has a constant vascular supply from the ascending branch of the LCFA with its accompanying commitant veins, and enters the muscle on its deep surface, from $6 \mathrm{~cm}$ to $8 \mathrm{~cm}$ below the iliac crest at the level of the greater trochanter. The skin is supplied by perforating branches through the muscle [13, 16, 28]. The LCFA blood vessel reaches the rectus femoris muscle and provides a branch for the lateral vastus muscle, while the branch supplying the TFL muscle is divided into 2 or 3 wide terminal branches [16]. Besides that, the proximal part of the TFL muscle is also vascularised by the superior gluteal artery, while the skin of the lateral tight region and the skin superficial to the muscle are vascularised by the perforating blood vessels arising from the TFL muscle $[8,19,32,39]$. This has a special significance in transpositional TFL flap.
Intraoperative negligence of variations of the TFL flap's vascularisation is a leading cause of the postsurgical flap necrosis. Understanding the TFL muscle blood supply allows a safe transposition of the muscle, as well as the skin superficial to it $[4,14,35,36]$.

The aims of the study are to define anatomical variations of the LCFA and its ascending branch which supplies the TFL flap, and to determine the skin area vascularised by perforating blood vessels from the TFL muscle.

\section{MATERIALS AND METHODS}

The study was performed of autopsy material, consisted of 100 foetuses, 59 male and 41 female; and ten adult male cadavers.

Both lower limbs of each studied foetus, varying in gestational age (from 5 to 10 lunar months, determined by parietal - coccyx length) were analysed for the number, origin, pathway and branching of the ascending branch of the LCFA, as well as for the manner of entrance into the TFL muscle. Some of the foetal cadavers with gestational age lower than 6 lunar months were excluded from the analysis because of the low calibre of examined blood vessels. The arteries were injected with micropaque solution, afterwards fixed and preserved in $10 \%$ formalin solution for approximately 6 months. Microdissection of the lower limbs was performed using the magnifying glass and the operating microscope.

Analysis of 10 adult cadavers (20 lower limbs), aged from 25 to 65 , was performed to determine the skin area vascularised by perforating blood vessels from the TFL muscle. All ten adults died of natural causes of death: myocardial infarction due to atherosclerosis ( 5 cases), congestive heart failure (2 cases), aortic stenosis (1 case), subarachnoid haemorrhage due to ruptured aneurysm (1 case), and bacterial pneumonia (1 case). There was not any fixation before the examination. All cadavers were proceeded to the medico-legal autopsy and the anatomical examination was performed before the autopsy. Following the dissection, the arteriotomy of the LCFA was performed, and $40 \mathrm{~mL}$ of methylene-blue dye (1\% solution) was injected into the artery through the cannula. Prior to the injection, all branches of the LCFA besides the ascending branch were ligated, in order to ensured visualisation of the skin area vascularised only by the perforating blood vessels from the TFL muscle, originating from the ascending branch of the LCFA. The length and the width of the skin area affected by dye were measured with millimetre-scale meter. 


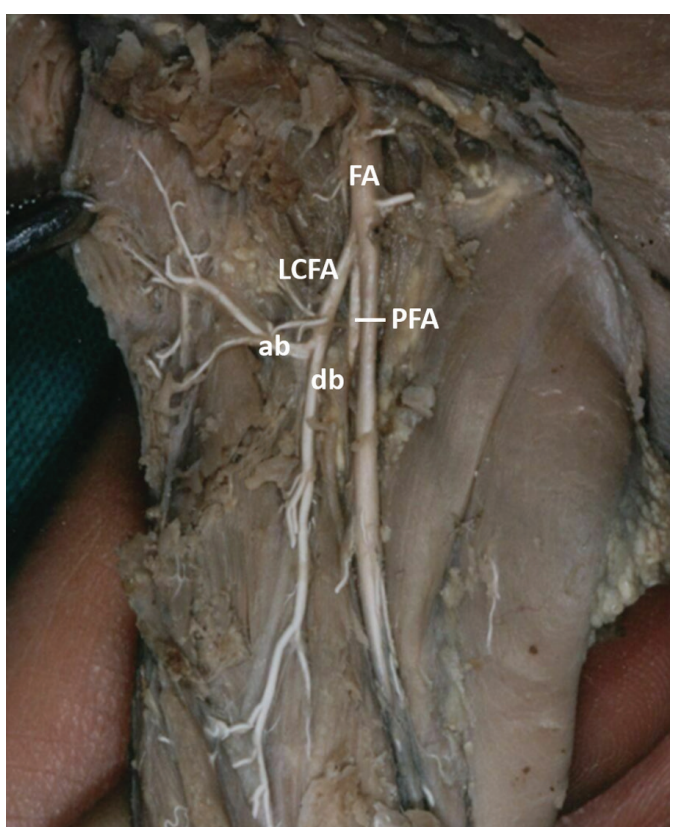

Figure 1. Branching in 2 terminal branches; FA - femoral artery; PFA — profunda femoris artery; LCFA — lateral circumflex femoral artery; $\mathrm{ab}$ — ascending branch; $\mathrm{db}$ — descending branch.

Beside descriptive statistics, a non-parametric ANOVA test for comparing differences in frequency is used in the study having in mind values of proportions; as well as Pearson's correlation and T-test.

\section{RESULTS}

The origin and the way of the ascending branch

Microdissections of 200 lower limbs show that LCFA gives two terminal branches in $85 \%$ (170/200): the ascending and the descending one (Fig. 1). In $8 \%$ $(16 / 200)$ of cases, the LCFA has also third terminal branch - the transverse one (Fig. 2). The LCFA is not present in $4 \%(8 / 200)$ of cases when the ascending and the descending branches arise as direct branches of the PFA, while in 3\% (6/200) of cases the ascending branch, descending branch and PFA divide by the common trunk from femoral artery (FA) directly. The origin of the ascending and the descending branches from some other blood vessel has not been noticed in this sample.

Regarding the cases of 2 terminal branches of the LCFA, the transverse terminal branch was the strongest branch of the ascending branch in $60 \%(102 / 170)$ cases, whilst in other $26 \%$ the stronger one was some other (Fig. 1), since for the rest it was not possible to determine which branch was the strongest due low calibre of vessels.

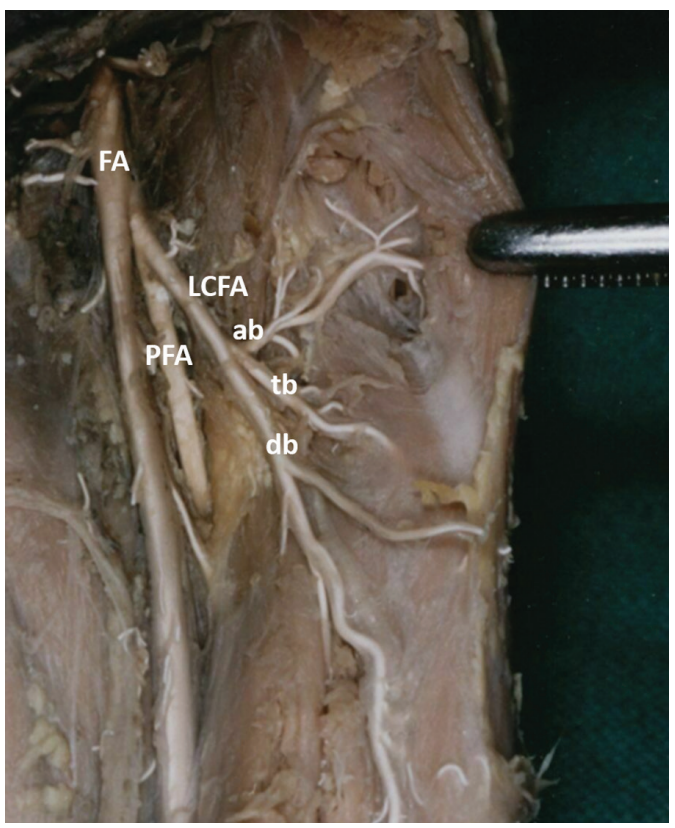

Figure 2. Branching in 3 terminal branches; FA — femoral artery; PFA — profunda femoris artery; LCFA — lateral circumflex femoral artery; $a b$ - ascending branch; tb — transverse branch; $\mathrm{db}-$ descending branch.

There were no statistical differences regarding gen$\operatorname{der}(p>0.05)$ and left/right lateralisation $(p>0.05)$.

The angle of bifurcation of the ascending and the descending branches and the pathway

The angle of bifurcation of the ascending and the descending branches after the branching from the LCFA is circa $90^{\circ}$ in $73 \%(124 / 170)$ of cases $(68 \%$ in males and $77 \%$ in females, without statistical difference, $p>0.05)$. The ascending branch has an almost horizontal pathway towards the TFL muscle in such cases.

The angle of bifurcation of the ascending and the descending branches is sharp in $27 \%$ (46/170) of cases. This way of bifurcation is noticed in cases of lower separation of the PFA, where the LCFA arises directly from the FA. In such cases, the direction of the ascending branch towards the muscle is almost vertical.

There was no statistical difference regarding left/ /right lateralisation $(p>0.05)$.

\section{The manner of entrance of the ascending branch into the TFL muscle}

For precise determining the entering site of the vascular stalk into the TFL muscle, the distance from the anterior superior iliac spine to the location where the TFL muscle transferred into the iliotibial tract was measured. In this way, the method of determination of the entering site of the vascular stalk into the TFL muscle was stan- 
dardised. Since the foetuses were different in gestational age, only the qualificative description of the entrance is given. We have noticed that the vascular stalk enters the muscle directly through its medial side in every case.

\section{The number of terminal branches of} the ascending branch of the LCFA

Results related to the number and the way of entrance of the terminal branches of the ascending branch into the TFL muscle show that the ascending branch can give a various number of terminal branches:

- $12 \%$ of cases show that it remains as a single blood vessel and entered the TFL muscle as a whole vessel;

- $28 \%$ of cases show the ascending branch bifurcating into 2 terminal branches prior to the entrance into the muscle. Those 2 terminal branches entered the TFL muscle through its medial side, in the middle of the determined distance;

- $45 \%$ of cases show the ascending branch dividing into 3 terminal branches prior to the entrance into the TFL muscle: the ascending, the descending, and the transverse ones. These 3 terminal branches enter the TFL muscle through various points on the determined distance;

- $7 \%$ of cases show the ascending branch dividing into more than 3 branches prior to the entrance into the TFL muscle. In such cases the ascending branch is divided into the ascending, the descending, and the transverse portion. The ascending portion divides into 2 smaller terminal branches entering the superior part of the TFL muscle; the descending portion also divides into 2 smaller terminal branches entering the inferior part of the TFL muscle; and the transverse portion remains undivided and enters the middle part of the TFL muscle as a single blood vessel. So, the maximal number of terminal branches was 5 ;

$-8 \%$ of cases show the ascending branch enters the muscle by forming an arterial net of vascularisation. The ascending branch divided into smaller branches that create anastomosis one with each other on the medial side of the TFL muscle, creating a net like formation entering the muscle.

Using the ANOVA statistics, the differences in frequency of manner of entrance of the ascending branch into the muscle is highly significant $(F=5.394, p<0.01)$, independently for the gender and the lateralisation. The difference mostly comes from the major number of division into 3 branches. By using the method of post-hoc analysis, we tested every single importance of the difference for the couples. The difference is significant when it comes to the anatomical division into 3 or 2 branches. The difference of frequency of the division into more than 3 branches (7\% of cases), a net ( $8 \%$ of cases) and a single branch ( $12 \%$ of cases) is not statistically significant to one another.

Due to low frequencies, gender and lateralisation related statistics were not performed.

\section{Skin area vascularisation by perforating blood vessels from the TFL muscle}

Ten adult cadavers were injected with methylene-blue into the LCFA with all branches ligated except the ascending one. The cadavers showed the area of the skin affected with dye which was ellipsoidal in all cases, presented on the lateral surface of thigh. The diameters of the skin area affected with dye are given in Table 1. Length of LCFA, as well as its diameter are in direct positive correlation with skin area affected with dye (Table 1).

The longer diameter of affected skin ellipse represents averagely $68 \%(\min 51 \%$, $\max 86 \%$ ) of the distance from anterior superior iliac spine to the Gerdy tubercle (lateral tibial condyle - area of roughness on the anterolateral side of the tibia slightly inferior from the joint space). The shorter ellipse diameter is averagely $36 \%$ ( $\min 22 \%$, max $55 \%$ ) of the thigh circumference observed on that point (Fig. 3).

The distance of the far distal point of the dyed skin area from the anterior superior iliac spine was measured, and the mean value was $24 \mathrm{~cm}$ (ranged $22-29 \mathrm{~cm}$ ).

There were no statistical differences in skin area affected with dye regarding gender $(p>0.05)$ and left/right lateralisation $(p>0.05)$.

\section{DISCUSSION}

The results of our study prove that the main blood supply of the TFL muscle is provided by the terminal branches of the ascending branch of the LCFA, which is indicated by some other authors as well $[12,13,16,21$, $28,36]$. The frequency of branches supplying the muscle was reported by Saadeh [28]. In that study, in $67 \%$ of cases a single dominant branch of the ascending branch supplied the muscle, in $13 \%$ another branch arising from the same ascending branch provided the additional supply and entering in the middle third, whereas in $20 \%$ of the cases the second vessel arose from the descending branch and was destined to the lower third of the muscle.

The results of our research show that the ascending branch arises from the LCFA in most cases. In $4 \%$ of cases the ascending and the descending branches arisen as direct branches of the PFA, while in $3 \%$ of cases the ascending branch, the descending branch and the PFA 
Table 1. Correlation coefficients (R) for the lateral circumflex femoral artery (LCFA) length and diameter with the skin area affected with dye

\begin{tabular}{lccccc}
\hline & $\begin{array}{c}\text { Mean } \\
\text { value }\end{array}$ & $\begin{array}{c}\text { Standard } \\
\text { deviation }\end{array}$ & Minimum & Maximum & $\begin{array}{c}\text { Correlation } \\
\text { coefficient }\end{array}$ \\
\hline LCFA length [mm] & 54 & 3.26 & 48 & 62 & 0.982 \\
LCFA diameter [mm] & 2.6 & 0.47 & 1.3 & 3.2 & 0.976 \\
Skin area affected with dye [cm] & $20 \times 24$ & Not applicable to & $18 \times 22$ & $23 \times 28$ & \\
$\begin{array}{l}\text { Far distal point from the anterior } \\
\text { superior iliac spine }\end{array}$ & 24 & 2.1 & 22 & 29 \\
\hline
\end{tabular}

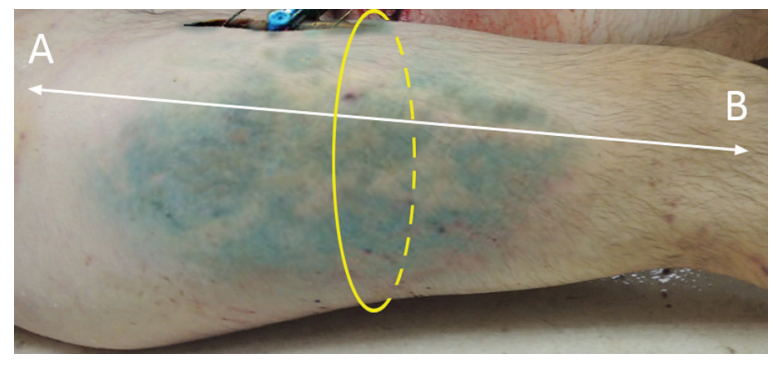

Figure 3. Skin area affected with dye. The white line represents the anterior superior iliac spine (A) - the Gerdy tubercle (B) distance. The circumference of the thigh at the point of maximal transversal diameter of the affected skin area is showed by the yellow ellipse.

divided with a common trunk from the FA. Similar data has been reported in literature. Usually, if the ascending and the descending branch are not divided from the LCFA, the case is that the ascending branch arises from the PFA and the descending branch from the FA, ranging from $0.9 \%$ to $3.2 \%[2,9,30,34]$. In some studies it was shown that they both arise from FA in different percentages $(0.5 \%, 0.9 \%$ and $1.5 \%)[2,9,34]$. Our material did not show the origin of the ascending and the descending branches from any other blood vessel, which has been presented by some other research $[29,35]$.

Our results also state that the LCFA gives two terminal branches, the ascending and the descending one, and that the transverse branch represents the strongest lateral branch of the ascending branch, since it usually arises from the ascending branch. Rarely, the transverse branch can be a direct branch of the LCFA or be missing. Sabancıogullari et al. [29], and Pan et al. [26] reported the same.

The ascending branch, which was of special significance to our research, ended near the great trochanter in all the cases, near the middle of the distance: the anterior superior iliac spine - location of the muscle fibres transferred into the iliotibial tract. Most authors share the opinion that the vascular stalk of the TFL muscle is from $8 \mathrm{~cm}$ to $10 \mathrm{~cm}$ inferior to the anterior superior iliac spine $[3,7,12,22,23,24,25]$. Jovanovic et al. [16] considered that to be incorrect and uncertain, and proposed that the point of orientation should be the greater trochanter. Through their study, the bifurcation of the terminal branches of ascending branch was $2.17 \mathrm{~cm}$ away from apex of greater trochanter, and since it is palpable, it is easy to rapidly determine the vascular pedicle of TFL muscle flap. This opinion was supported by Gosain et al., too [10]. However, we think that the great trochanter is a significant point in orientation but not precise enough. The ascending branch, which is dominant in the vascularisation of the flap as a unique vessel, or its terminal branches which arise prior to the entrance into the muscle, enter the TFL muscle in various levels of the determined distance (anterior superior iliac spine - the location of muscle fibres transferring into the iliotibial tract), most commonly in the middle $[1,6]$.

The understanding that the bifurcation of the ascending branch of the LCFA enters the TFL muscle directly is of great importance when planning the flap $[1,21,36]$. The results of our study show that the number of terminal branches of the ascending branch which arise prior to the entrance into the muscle was $0-8$. In most cases (45\%) the number of the terminal branches is 3 , which data is not supported by the literature stating that the number of branches of the ascending branch is usually $2[12,20,21,36,37]$, except with the study conducted by Jovanovic et al. [16].

The pathway of the ascending branch and the angle of bifurcation depend on the way of appearance and correlate with the origin, or the way of appearance of the LCFA. The angle of bifurcation of the ascending and the descending branches is in most 
cases almost right, and the pathway of the ascending branch is horizontal in such cases. Less frequently, the angle of bifurcation of the ascending and the descending branches is sharp, and the pathway of the ascending branch is vertical towards the muscle. This way of bifurcation and the pathway of the ascending branch are noticed in the cases of inferior separation of the PFA from the FA in the femoral triangle of Scarpa, when the LCFA separated directly from the FA. The understanding of the way of separation, the angle of bifurcation, the pathway, with the way of entrance of the ascending branch into the muscle is of great importance in assessing the vascular stalk during reconstructions or graft application $[1,4,6$, $10,36,37]$.

Some authors share the opinion that the TFL muscle is vascularised by the descending branch of the LCFA [29], or even by the transverse branch of the LCFA, where 5 to 7 perforator vessels are always present [14], which was not noticed in our sample.

The average skin area dyed on the TFL flap, vascularised by the perforating branches of the ascending branch of the LCFA was $20 \times 24 \mathrm{~cm}-$ similar to the data from the literature $[14,16,35]$. The distance of the far distal point of the dyed skin area from the anterior superior iliac spine was $24 \mathrm{~cm}$ in average, which is a point of orientation in length of the rotation arc of the flap in surgery [14]. The TNF flap is ellipsoidal in shape and represents averagely $68 \%$ of the distance from anterior superior iliac spine to the Gerdy tubercle, and averagely $36 \%$ of the thigh circumference.

Knowledge of the characteristics of the vascular stalk of the TFL muscle, and especially the anatomical variances, has an extraordinary significance in planning and successful using of the TFL flap, transpositional ones, as well as free flaps $[1,10,15,18]$. Transposistional TFL flap sufrace is larger than the free flap surface, which is due to the vascularisation of the TFL muscle both by the LCFA and the superior gluteal artery as an accessory vascular branch $[8,19,32,39]$. It enters the TFL muscle proximally and therefore it is not compromised during the elevation of the transpositional TFL flap. On the other hand, in elevation of free flap, it is divided and ligated. Therefore, all attemps performed by some authors to transfer a free TFL flap with the surface matching the size of the transpositional TFL flap resulted in distal flap necrosis. So, the surface of free TFL flap is based strictly on the vascular pedicle of ascending branch of LCFA alone, and its area of vascularisation should be delineated by prior colour-ink injection. This procedure allows demarcation of the tissue that may be raised safely as a free TFL flap. Elevation of a larger surface leeds to partial flap necrosis $[4,7,13,25,32]$.

\section{CONCLUSIONS}

The ascending branch of the LCFA plays a dominant role in vascularisation of the TFL muscle. The location of entrance of the terminal branches of the ascending branch of the LCFA into the TFL flap is in different levels of the distance between the anterior superior iliac spine and the location of muscle fibres transferring into the iliotibial tract, but most commonly in the middle of it. The ascending branch may enter the muscle undivided or divided into terminal branches, mostly in 3 of them. The pathway and the angle of bifurcation of the ascending branch correlate with the way of appearance. The angle of bifurcation of the ascending and the descending branches, in most cases is almost $90^{\circ}$, and in such cases the pathway of the ascending branch is horizontal. Less frequently the angle is sharp, noticed in the cases of lower separation from the PFA where the LCFA arisen directly from the FA. In such cases, the pathway of the ascending branch is vertical. The skin area vascularised by the perforating blood vessels of the TFL flap is $20 \times 24 \mathrm{~cm}$, average. The TFL flap is ellipsoidal in shapeand represents averagely $68 \%$ of the distance from anterior superior iliac spine to the Gerdy tubercle, and averagely $36 \%$ of the thigh circumference. The distance of the far distal point of the skin area dyed from the anterior superior iliac spine is on average $24 \mathrm{~cm}$, which is an orientation point for the length of rotation arc of the flap during surgery.

\section{ACKNOWLEDGEMENTS}

Ethical Committee of Medical faculty, University of Nis, Serbia, approved the research. The study is a part of PhD thesis of the first author, conducted in that University.

\section{REFERENCES}

1. Agarwal AK, Gupta S, Bhattacharya N, Guha G, Agarwal A (2009) Tensor fascia lata flap reconstruction in groin malignancy. Singapore Med J, 50: 781-784.

2. Bergman RA, Afifi AK, Myauchi R (1996) Illustrated encyclopedia of human anatomic variation. Opus II: Cardiovascular system. Arteries. Lower limb, medial and lateral femoral circumflex arteries. Available at: http:// www.anatomyatlases.org.

3. Bhathena HM, Kavarna NM (1993) One stage reconstruction of extensive abdominal wall defect with bilateral tensor fascia lata flap. Indian J Cancer, 30: 10-15. 
4. Caffee H, Asokan R (1981) Tensor fascia lata myocutaneous free flaps. Plast Reconstr Surg, 68: 195.

5. Contedini F, Negosanti L, Pinto V, Tavaniello B, Fabbri E, Sgarzani R, Tassone D, Cipriani R (2013) Tensor fascia latae perforator flap: an alternative reconstructive choice for anterolateral thigh flap when no sizable skin perforator is available. Indian J Plast Surg, 46: 55-58.

6. Demirseren E, Gokrem S, Ozdemir OM, Can Z, Serel S (2003) Hatchet shaped tensor fascia lata musculocutaneous flap for the coverage of trochanteric pressure sores: a new modification. Ann Plast Surg, 51: 419-422.

7. Endo T, Nakayama Y, Soeda S (1991) Reconstruction of the cheek and palate using a three-paddle tensor fasciae latae free flap. Br J Plast Surg, 44: 234-235.

8. Ercocen AR, Apaydin I, Emiroglu M, Yilmaz S, Adanali G, Tekdemir I, Yormuk E (1998) Island V-Y tensor fasciae latae fasciocutaneous flap for coverage of trochanteris pressure sores. Plast Reconst Surg, 102: 1524-1531.

9. Fukuda H, Ashida M, Ishii R, Abe S, Ibukuro K (2005) Anatomical variants of the lateral circumflex artery: an angiographic study. Surg Radiol Anat, 27: 260-264.

10. Gosain AK, Yan JG, Aydin MA, Das DK, Sanger JR (2002) The vascular supply of extended tensor fasciae latae flap: how far can the skin paddle extend? Plast Reconstr Surg, 110: 1655-1663.

11. Gruen R, Morrison W, Vellar I (1998) The tensor fasciae latae myocutaneous flap closure of major chest and abdominal wall defects. Aust N Z J Surg, 68: 666-669.

12. Gurunluoglu R (2010) The ascending branch of the lateral circumflex femoral vessels: review of the anatomy and its utilization as recipient vessel for free-flap reconstruction of the hip region. J Reconstr Microsurg, 26: 359-366.

13. Hill HL, Nahai F, Vascones LO (1978) The tensor fascia lata myocuteous free flap. Plast Reconstr Surg, 61: 517-522.

14. Hubmer MG, Schwaiger N, Windisch G, Feigl G, Koch H, Haas FM, Justich I, Scharnagl E (2009) The vascular anatomy of the tensor fasciae latae perforator flap. Plast Reconstr Surg, 124: 181-189.

15. Ishida LH, Munhoz AM, Montag E, Alves HR, Saito FL (2005) Tensor fasciae latae perforator flap: minimizing donor-site morbidity in the treatment of trochanteric pressure sores. Plast Reconstr Surg, 116: 1346-1352.

16. Jovanovic $M$, Colic $M$. Stefanovic $P$, Ronevic R, Rasulic $L$, Karapandic M (2004) Anatomic analysis of the vascular network and vascular pedicle of the tensor fascia lata flap (angiographic and cadaver study). Eur J Plast Surg, 27: 61-67.

17. Kawai K, Imanishi N, Nakajima H, Aiso S, Kakibuchi M, Hosokawa K (2004) Vascular anatomy of the anterolateral thigh flap. Plast Reconstr Surg, 114: 1108-1117.

18. Kimata $Y$, Uchiyama K, Ebihara S, Sakuraba M, lida $H$, Nakatsuka T, Harii K (2000) Anterolateral thigh flap donor-site complications and morbidity. Plast Reconstr Surg, 106: 584.

19. Kimata $Y$, Uchiyama $K$, Sekido $M$, Sakuraba $M$, Lida $H$, Nakatsuka T, Harii K (1999) Anterolateral thigh flap for abdominal wall reconstruction. Plast Reconstr Surg, 103: 1191-1197.
20. Kimura N, Saito M, Itoh Y, Sumiya N (2006) Giant combined microdissected thin thigh perforator flap. J Plast Reconstr Aesthet Surg, 59: 1325-1329.

21. Luo S, Raffoul W, Piaget F, Egloff DV (2000) Anterolateral thigh fasciocutaneous flap in the difficult perineogenital reconstruction. Plast Reconstr Surg, 105: 171-173.

22. Mathes JS, Nahai F (1979) Clinical atlas of muscle and musculocutaneous flaps. Mosby, St. Louis, pp. 63-68.

23. Mathes JS, Nahai F (1982) Clinical applications for muscle and musculocutaneous flaps. Mosby, St. Louis, pp. 99-151.

24. Muller-Vahl H (1985) Isolated complete paralysis of tensor fasciae latae muscle. Eur Neurol, 24: 289-291.

25. Nahai F, Hill L, Hester TR (1979) Experiences with the tensor fascia lata flap. Plast Reconstr Surg, 63: 788-799.

26. Pan SC, Yu JC, Shieh SJ (2004) Distally based anterolateral thigh flap: an anatomic and clinical study. Plast Reconst Surg, 114: 1768-1775.

27. Rifaat MA, Gawad WSA (2005) The use of tensor faciae lata pedicled flap in reconstructing full thickness abdominal wall defects and groin defects following tumor ablation. J Egypt Natl Canc Inst, 17: 139-148.

28. Saadeh FA, Haikal FA, Abdel-Hamid FA (1998) Blood supply of the tensor fasciae latae muscle. Clin Anat, 11: 236-238.

29. Sabanciogullari V, Kosar MI, Olcu E, Cimen M (2009) The deep femoral artery and branching variations: a case report. Cumhuriyet Med J, 31: 279-282.

30. Siddarth P, Smith NL, Mason RA, Giron F (1985) Variational anatomy of the deep femoral artery. Anat Rec, 212: 206-209.

31. Standring S (2008) Gray's anatomy. The anatomical basis of the clinical practice. $40^{\text {th }} \mathrm{Ed}$, Churchill Livingston Elsevier, London, p. 1380.

32. Stefanovic P, Jovanovic M, Antoniou A (2000) Review of the vascular territory of tensor fasciae latae flap. [Article in Serbian] Medicinska Istrazivanja, 34: 5-11.

33. Tukiainen E, Leppaniemi A (2011) Reconstruction of extensive abdominal wall defects with microvascular tensor fasciae latae flap. Br J Surg, 98: 880-884.

34. Uzel M, Tanyeli E, Yildrim M (2008) Anatomical study of the origin of LCFA in Turkish population. Folia Morphol, 67: 226-230.

35. Valdatta L, Tuinder S, Buoro M, Thione A (2002) Lateral circumflex femoral arterial system and perforators of the anterolateral thigh flap: an anatomic study. Ann Plastic Surg, 49: 145-150.

36. Vegas MR, Martin-Hervas C (2013) The superolateral thigh flap: cadaver and computed tomographic angiography studies with a clinical series. Plast Reconstr Surg, 131: 310-322.

37. Vuksanovic A, Ugrenovic S, Jovanovic I (2006) Vascular stalk analysis of the tensor fasciae latae flap. Facta Universitatis, Series Medicine and Biology, 13: 1-5.

38. Wangesteen $\mathrm{OH}$ (1934) Repair of recurrent and difficult hernias and other larger defects of the abdominal wall employing the iliotibial tract of fascia lata as pedicled flap. Surg Gynecol Obstet, 59: 766-780.

39. Yousif NJ, Ye Z (1991) Analysis of cutaneous perfusion: an aid to lower extremity reconstruction. Clin Plast Surg, 18: 559-570. 